\title{
INFLUENCE OF WAVE FORM ON THE RATE OF INTEGRATING INDUCTION METERS.
}

\author{
By E. B. RosA, M. G. Lloyd, and C. E. Reid.
}

We give in this paper the results obtained with five integrating induction wattmeters, on which we have made a large number of tests, although further work remains to be done. These results may therefore be regarded as preliminary, illustrating the methods employed and the results obtained when changes are made in the wave form by altering the magnitude or phase of the harmonics present.

Two of the meters employed were sent to the Bureau of Standards for test by the makers. The others were meters which we happened to have in the laboratory when the tests were undertaken. The following is a list of the meters:

\footnotetext{
No. 1, Stanley (magnetic suspension type), 50 amperes.

No. 2, Stanley (magnetic suspension type), 50 amperes.

No. 3, Fort Wayne, type " $\mathrm{K}$," 50 amperes.

No. 4, General Electric (1902 House type), 25 amperes.

No. 5, Siemens \& Halske, 25 amperes.
}

All the meters are made for 60 cycles, single phase. The first four are American instruments; the last is of German make. Each meter was tested at full load and at 110 volts, and at approximately unity power factor.

In order to determine the effect on the rate of an induction meter due to varying the wave form, it is necessary to eliminate carefully any effects due to variation in the temperature of the meter or changes in the frequency of current, or other alterations in the conditions of the meter or circuit. In most cases the effect of a moderate distortion of the wave is small, and unless all measurements are made with great care the effects looked for may be masked by other effects or by errors of measurement. The meters were tested alternately with current of sine wave form and with a distorted wave, the distortion being produced by adding a harmonic of three times the frequency 


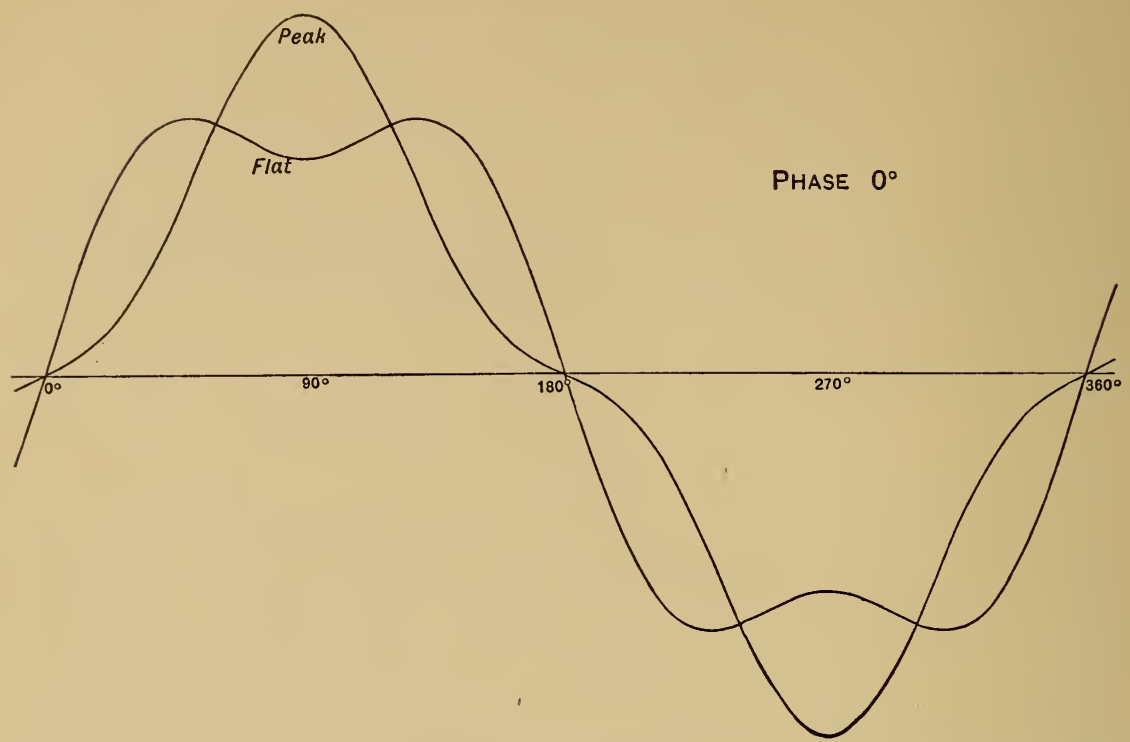

FIG. 1.-Showing the resultant of combining the fundamental and harmonic of three times the frequency and 25 per cent of the magnitude of the fundamental, giving first a peaked wave and second (when the phase of the harmonic is reversed) a flat or dimpled wave. Both fundamental and harmonic are of sine-wave form.

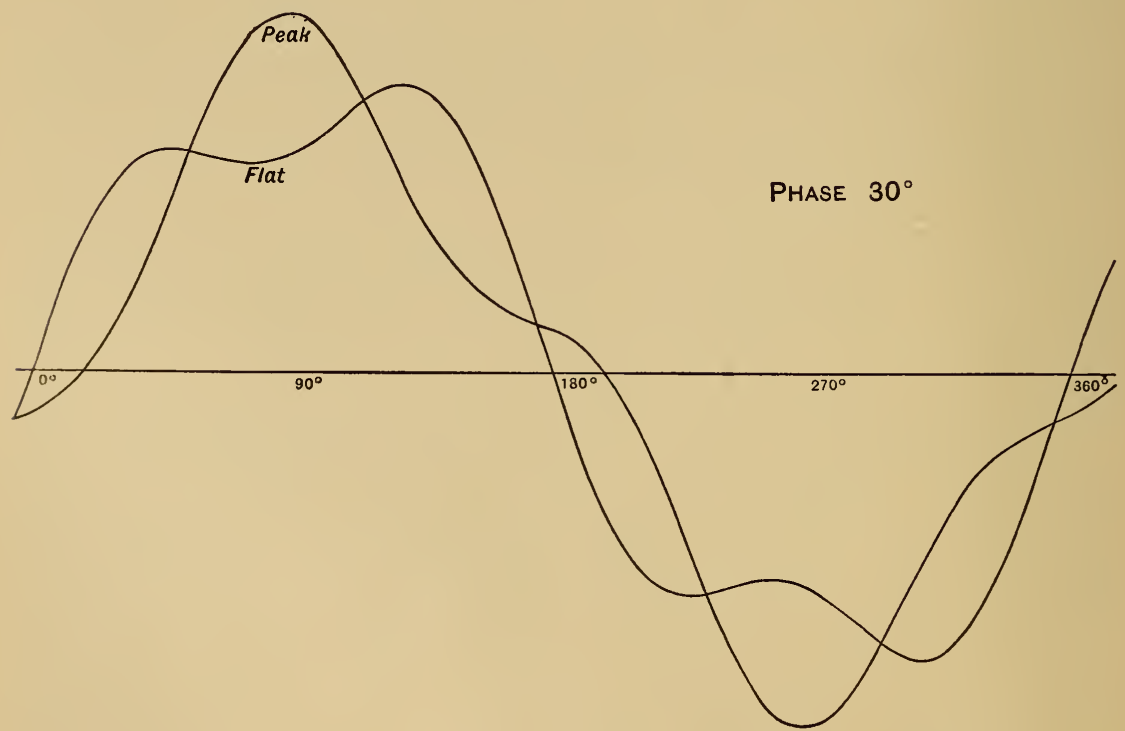

FIG. 2.-Showing the resultant of a fundamental and a harmonic, as in fig. 1, except that the phase of the harmonic has been shifted $30^{\circ}$ by changing the coupling $5^{\circ}$. 


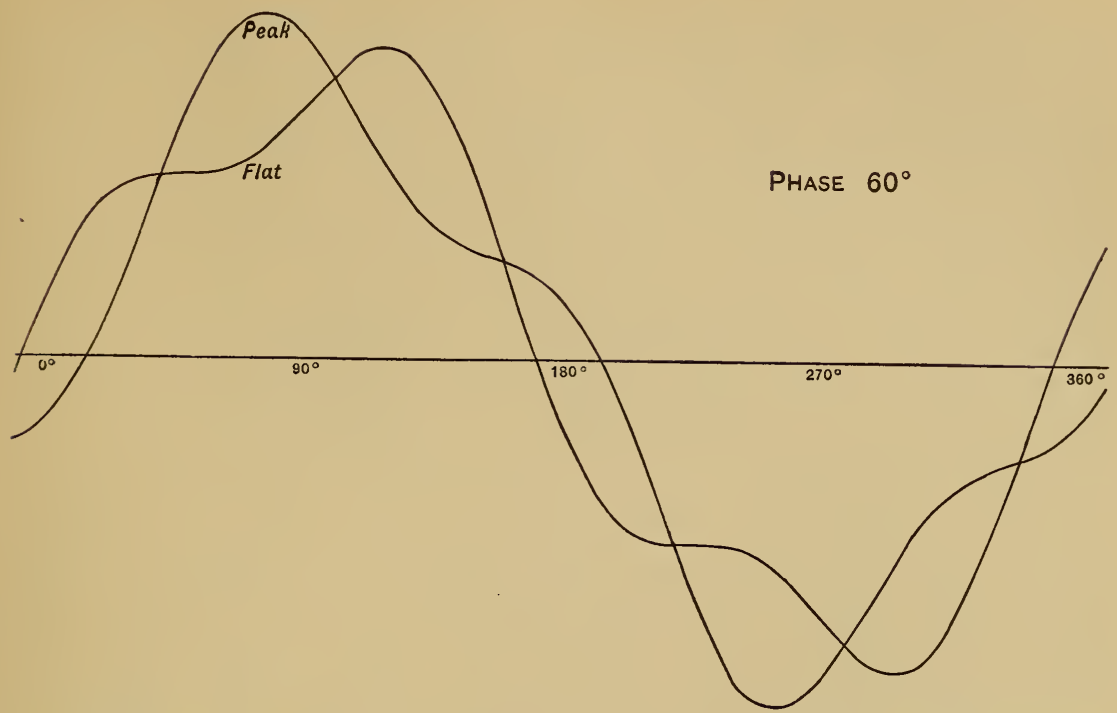

FIG. 3.-Showing the resultant of a fundamental and a harmonic as in fig. 1, except that the phase of the harmonic has been shifted $60^{\circ}$.

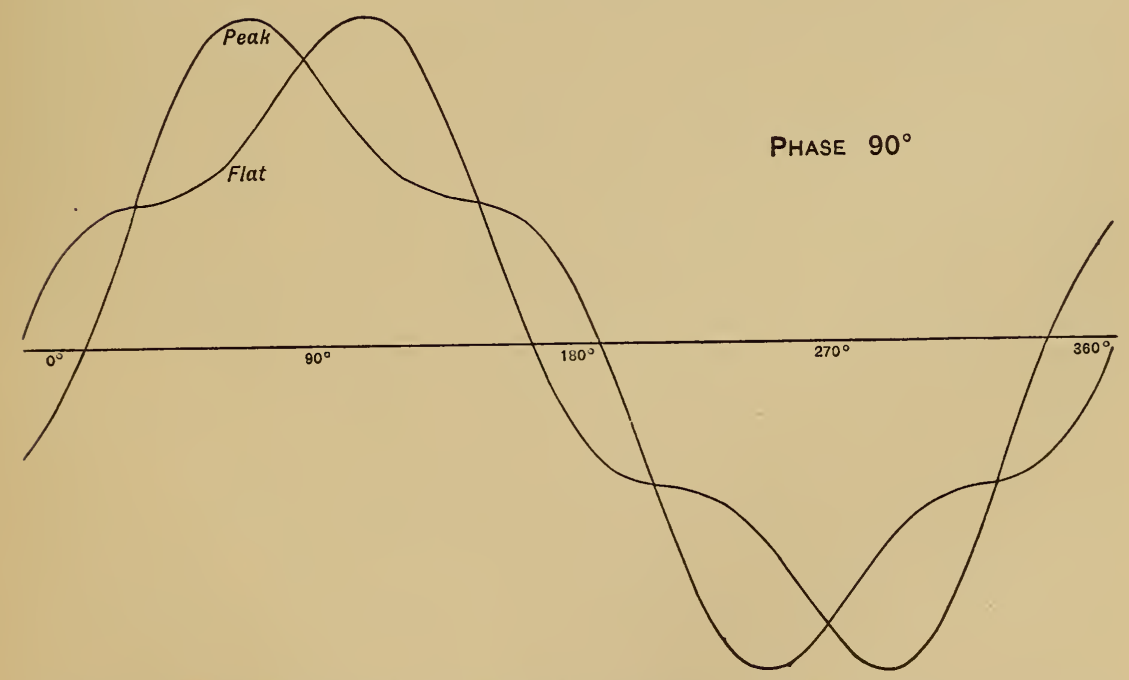

FIG. 4.-Showing the resultant of a fundamental and a harmonic as in fig. 1, except that the phase of the harmonic has been shifted $90^{\circ}$ by changing the coupling $15^{\circ}$. The wave form for "peak" and "flat" are here alike, except that the steeper side is in advance in the "peak" and the more gradual slope is in advance on the "flat." "Peak" and "flat" are conventional terms, indicating the phase of the harmonic. If the coupling were shifted $15^{\circ}$ more, the "flat" curve would become peaked. 
of the fundamental, varying both the amplitude and phase of this harmonic. This was done by means of an alternating current generating set of three machines, two alternators and a direct connected driving motor, one alternator having four poles and the other twelve. The current from each machine is very nearly of sine wave form, and tests were made of the meters alternately with the fundamental only, and with the harmonic added. Three different relative values and four different phases of the harmonic have been employed. The three values of the harmonic are 10 per cent, 25 per cent, and 50 per cent, respectively, of the value of the fundamental. For example, since $E=\sqrt{E^{2}{ }_{1}+E^{2}}$, in the first case the addition of 11 volts of the harmonic to 110 volts of the fundamental gives a resultant of about 110.5 volts, the wave being more or less peaked than a sine wave, according to the phase of the harmonic. In the second case 108 volts of the fundamental plus 27 volts of the harmonic gives a resultant of 111.3 volts. (The voltage in each case was reduced to exactly 110 by resistance in series.) This resultant is shown in figs. 1 to 4 , where the 25 per cent harmonic is in different phase in each of the four cases. This difference is produced by shifting the coupling of one of the generators to the driving motor, $5^{\circ}$, $10^{\circ}$, or $15^{\circ}$ in the coupling corresponding to $10^{\circ}, 20^{\circ}$, or $30^{\circ}$ in the wave of the fundamental, and to $30^{\circ}, 60^{\circ}$, or $90^{\circ}$ in the phase of the harmonic. A shift of $30^{\circ}$ in the coupling corresponds to $180^{\circ}$ in the phase of the harmonic, and is the same as reversing the phase by reversing the connections at the terminals of the higher frequency generator. The latter is of course the more convenient, and was the usual method of changing from what we call a flat to a peaked wave. The curves shown in figs. 1 to 4 have been frequently verified by drawing the resultant waves by means of a curve tracer. This not only verifies the wave form, but serves to insure against errors in the connections.

The current, voltage, and power factor, as well as the temperature and frequency, were maintained as nearly constant as possible during a set of runs. A standard wattmeter which was calibrated by direct currents using two potentiometers to measure simultaneously the current and the voltage, was read by a telescope and scale. By means of a carbon rheostat the deflection of this instrument was maintained accurately constant while carrying alternating current during a set of runs on the meters. The wattmeter is of the dynamometer type and astatic. The fixed coils are stranded and wound on wooden spools, and very little metal is used in the region of the coils. The movable coils have very slight inductance, and every precaution is taken to avoid errors due to eddy currents or wave form. The instrument, being 
carefully calibrated with direct current, is then correct for alternating current.

Table I.-Determination of the Tines of Revolution of the Disks of Three Meters.

RUN NO. 1, MAY 26, 1904.

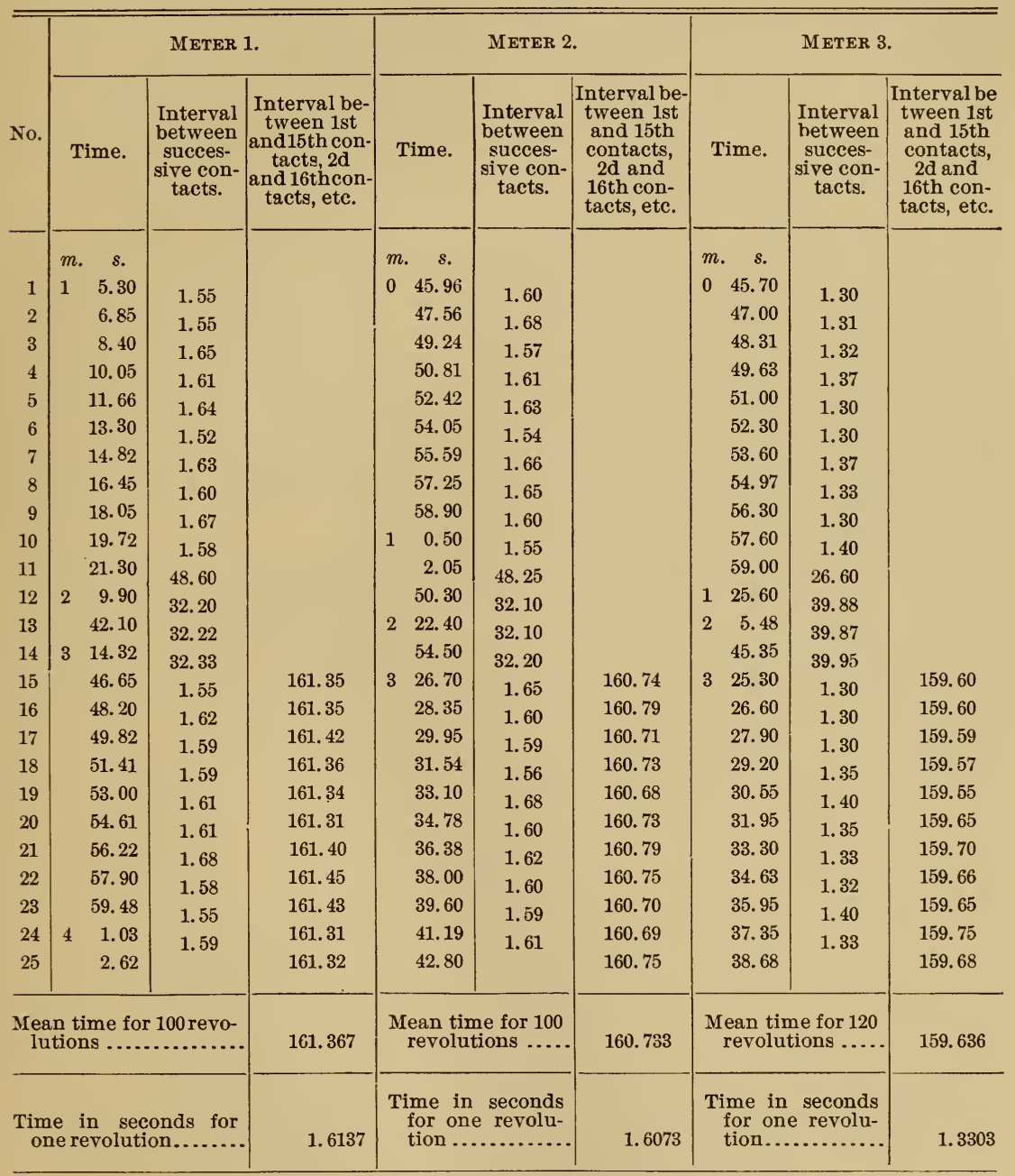

\section{DETERMINATION OF THE RATE OF THE METERS AND THE FREQUENCY OF THE CURRENT.}

The rate of the meters was determined by means of a chronograph and chronometer, record being made at the end of every revolution of the disk or drum for the first ten revolutions at the beginning of a 
run and the last ten at the end of the run, and in addition once in ten or twenty revolutions during the run. The runs average about three minutes each. The record on the chronograph sheet was read by means of a diagonal scale and gave the mean time of one revolution with great accuracy. An example is given in Table I. Eleven independent determinations of the time of 100 revolutions of the disk are given in the fourth and seventh columns for meters 1 and 2 and of 120 revolutions in the tenth column for meter 3. The average of these eleven values is used in deriving the mean time for one revolution. At the same time an electric circuit was closed by a contact point connected to the generator once in every hundred revolutions, and these contacts were recorded on the chronograph sheet. This gave the frequency of the current very exactly. A slight correction is applied to the rate of each meter for the small departure of the frequency from 60 , which is the standard frequency for the meters tested. This correction is of course determined for each meter separately and may be taken from the curves in fig. 10. In Table II are given the readings from the chronograph record for determining the frequency of the current, which in this case averaged 59.95 for the period of the run.

Table II.-Record for Determination of the Frequency of the Current.

\begin{tabular}{|c|c|c|}
\hline $\begin{array}{l}\text { Time of contacts at begin- } \\
\text { ning of run. }\end{array}$ & $\begin{array}{l}\text { Time of contacts at end } \\
\text { of run. }\end{array}$ & Time for 5,100 revolutions. \\
\hline $\begin{array}{rr}m . & s . \\
1 & 3.25 \\
& 6.60 \\
9.92 \\
13.28 \\
\\
16.60\end{array}$ & \begin{tabular}{cc}
$m$. & \multicolumn{1}{c}{$s}$. \\
3 & 53.40 \\
& 56.73 \\
4 & 0.05 \\
& 3.40 \\
& 6.75
\end{tabular} & $\begin{array}{c}\text { Seconds. } \\
170.15 \\
170.13 \\
170.13 \\
170.12 \\
170.15\end{array}$ \\
\hline
\end{tabular}

Mean $=170.136$

Frequency $=\frac{2 \times 5,100}{170.136}=59.95$ cycles per second.

Before making a series of runs on the meters the load was applied and they were warmed up to an equilibrium temperature. In order to eliminate errors due to any changes in temperature that might subsequently occur, as well as any other constant errors due to changing conditions, and so obtain the effect of the varying wave form alone, the tests with distorted wave forms were interspersed with tests using sine wave forms. Any progressive change in the meters, or the standard wattmeter, would thus be eliminated. Table III gives the 
results of 49 runs on three meters made May 26, 1904, using a sine wave and a distorted wave due to 25 per cent harmonic, peak and flat, as shown in figs. 1 to 4 . The numbers of the runs show the order in which they were taken. For example, the first, fourth, and seventh were made with a sine wave and are grouped together in the table. The actual frequency for each run is given in the table, but the times of one revolution given in columns 6,8 , and 10 have been reduced to 60 cycles. The numbers given in columns 7,9 , and 11 are the means of the corresponding values in columns 6,8 , and 10 .

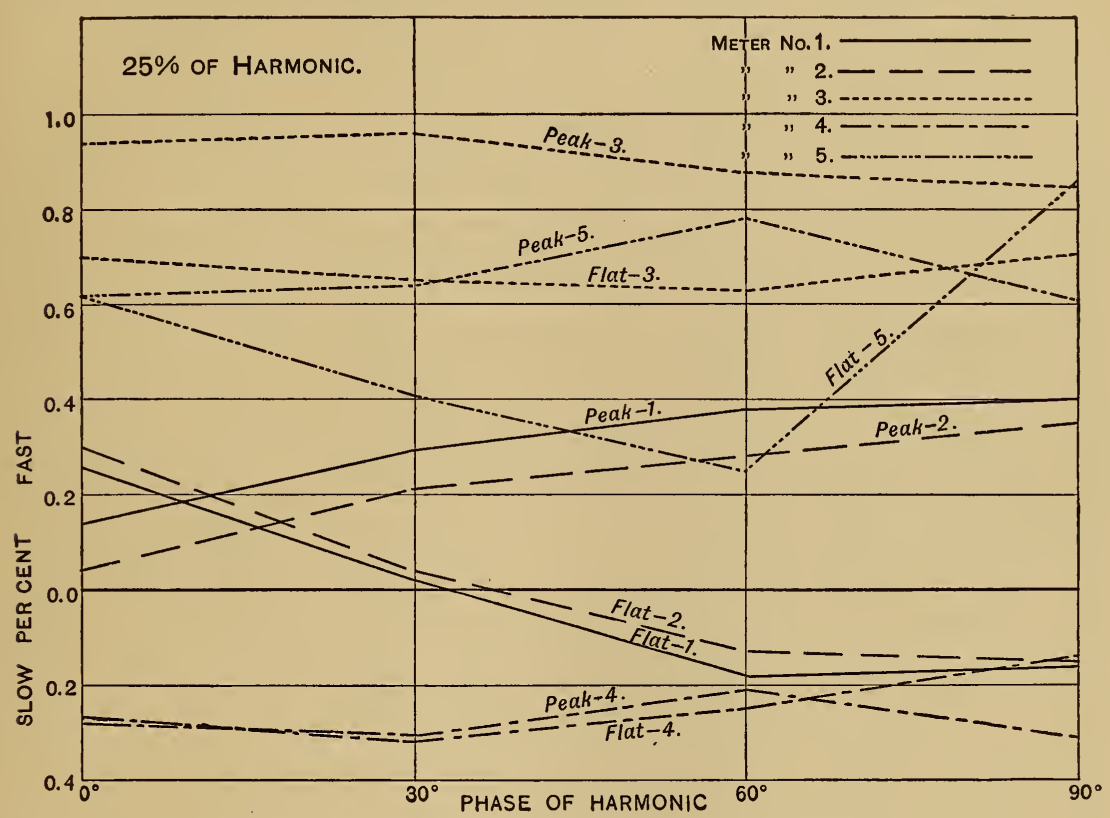

FIG. 5.-Showing the variation in the rate of five induction meters with 25 per cent harmonic in the current as the phase of the harmonic is changed from $0^{\circ}$ to $30^{\circ}, 60^{\circ}$, and $90^{\circ}$.

Runs 2 and 5 were made using a peaked wave and runs 3 and 6 using a flat wave. The phase of the harmonic was then shifted $30^{\circ}$, and seven runs made in the same order as before. The third set of seven runs was made with the harmonic at $60^{\circ}$, the fourth set at $90^{\circ}$, and then three more sets of runs were made in reverse order with respect to the phase of the harmonic, making in all seven sets of seven runs each. The difference in per cent obtained in Table IV, together with corresponding differences in other runs using 10 and 50 per cent harmonic, the detailed results of which are not here given, are shown in Table V. All these results are plotted in figs. 5 to 9 . The results obtained in the runs of May 26, given in Tables III and IV, are plotted in fig. 5 . 
Table III.-Table of Results of 49 Runs on Three Meters Using Sine, Peak and Flat Wayes, with Different Phases of the Harmonic, which is 25 Per Cent of the Fundamental.

\begin{tabular}{|c|c|c|c|c|c|c|c|c|c|c|}
\hline \multirow{3}{*}{ 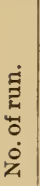 } & \multirow{3}{*}{$\begin{array}{c}\text { Phase } \\
\text { of } \\
\text { har- } \\
\text { monic. }\end{array}$} & \multirow{3}{*}{$\begin{array}{c}\text { Lag of } \\
\text { cur: } \\
\text { rent. }\end{array}$} & \multirow{3}{*}{$\begin{array}{l}\text { Wave } \\
\text { form. }\end{array}$} & \multirow{3}{*}{$\begin{array}{c}\text { Fre- } \\
\text { quency. }\end{array}$} & \multicolumn{6}{|c|}{ Time in seconds for one revolution of disk. } \\
\hline & & & & & \multicolumn{2}{|c|}{ Meter No. 1.} & \multicolumn{2}{|c|}{ Meter No. 2.} & \multicolumn{2}{|c|}{ Meter No. 3.} \\
\hline & & & & & Time. & Mean. & Time. & Mean. & Time. & Mean. \\
\hline 1 & & 19.8 & Sine .... & 59.95 & 1.6137 & \multirow{3}{*}{1.6154} & 1.6073 & \multirow{3}{*}{1.6084} & 1.3303 & \multirow{3}{*}{ 1. 3308} \\
\hline 4 & $\cdots$ & 18.9 & Sine .... & 60.35 & 1. 6178 & & 1.6109 & & 1.3321 & \\
\hline 7 & & 18.6 & Sine .... & 60.23 & 1.6148 & & 1.6071 & & 1.3300 & \\
\hline 2 & 0 & 19.8 & Peak ... & 59.89 & 1.6180 & \multirow{2}{*}{1.6183} & 1.6093 & \multirow{2}{*}{ 1. 6099} & 1.3438 & \multirow{2}{*}{1.3431} \\
\hline 5 & 0 & 19.0 & Peak ... & 60.31 & 1.6187 & & 1.6105 & & 1. 3425 & \\
\hline 3 & 0 & 17.0 & Flat & 60.38 & 1.6203 & \multirow{2}{*}{ 1. 6193} & 1.6141 & \multirow{2}{*}{1.6131} & 1. 3407 & \multirow{2}{*}{1.3398} \\
\hline 6 & 0 & ......... & Flat.... & 60.26 & 1. 6184 & & 1.6121 & & 1. 3390 & \\
\hline 8 & & & Sine .... & 59.96 & 1.6121 & \multirow{3}{*}{1.6148} & 1.6051 & \multirow{3}{*}{ 1. 6077} & 1. 3289 & \multirow{3}{*}{ 1. 3305} \\
\hline 11 & & 20.0 & Sine & 60.08 & 1. 6169 & & 1.6099 & & 1. 3320 & \\
\hline 14 & & 19.2 & Sine... & 59.95 & 1.6153 & & 1. 6082 & & 1. 3307 & \\
\hline 9 & 30 & 19.1 & Peak ... & 60.09 & 1. 6197 & \multirow{2}{*}{1.6199} & 1. 6116 & \multirow{2}{*}{ 1. 6120} & 1.3440 & \multirow{2}{*}{1.3441} \\
\hline 12 & 30 & 19.3 & Peak ... & 59.98 & 1.6202 & & 1.6125 & & 1.3443 & \\
\hline 10 & 30 & 17.7 & Flat. & 60.12 & 1. 6149 & \multirow{2}{*}{1.6152} & 1. 6091 & \multirow{2}{*}{1.6092} & 1.3405 & \multirow{2}{*}{1.3404} \\
\hline 13 & 30 & 17.0 & Flat. & 59.99 & 1. 6155 & & 1. 6092 & & 1. 3404 & \\
\hline 15 & & 19.5 & Sine. & 60.14 & 1. 6148 & & 1.6089 & & 1. 3309 & \\
\hline 18 & ... & 18.9 & Sine.... & 60.04 & 1. 6158 & 1. 6156 & 1.6086 & 1. 6088 & 1.3306 & 1. 3309 \\
\hline 21 & $\cdots$ & 18.3 & Sine. & 59.90 & 1.6162 & & 1. 6088 & & 1.3311 & \\
\hline 16 & 60 & 17.9 & Peak ... & 60.10 & 1. 6214 & 1.6216 & 1.6127 & 1.6133 & 1.3423 & 13426 \\
\hline 19 & 60 & 17.2 & Peak ... & 60.12 & 1.6219 & 1.6216 & 1.6140 & 1.6133 & 1.3429 & 1.3426 \\
\hline 17 & 60 & 16.6 & Flat .... & 60.05 & 1. 6127 & 1126 & 1.6063 & 16061 & 1.3393 & 3391 \\
\hline 20 & 60 & 15.9 & Flat .... & 59.94 & 1. 6125 & 1.6126 & 1.6059 & 1.6061 & 1.3390 & 1.3391 \\
\hline 22 & & 20.2 & Sine & 60.28 & 1. 6151 & & 1.6076 & & 1.3302 & \\
\hline 25 & & ....... & Sine .... & 60.10 & 1.6152 & 1.6151 & 1.6084 & 1.6079 & 1.3307 & 1.3305 \\
\hline 28 & $\cdots$ & 19.8 & Sine.... & 60.05 & 1. 6150 & & 1. 6077 & & 1.3306 & \\
\hline 23 & 90 & 18.9 & Peak ... & 60.18 & 1. 6211 & 11016 & 1. 6133 & 10126 & 1.3417 & 13419 \\
\hline 26 & 90 & 18.3 & Peak ... & 60.07 & 1. 6222 & 1.6216 & 1. 6138 & .6136 & 1. 3422 & 1.3419 \\
\hline 24 & 90 & 18.0 & Flat. & 60.10 & 1. 6124 & 6125 & 1.6056 & 1.6054 & 1.3401 & 1.3400 \\
\hline 27 & 90 & ..... & Flat & 60.04 & 1. 6127 & 1.6120 & 1.6052 & 1.6054 & 1. 3399 & \\
\hline 29 & & 19.3 & Sine.... & 59.86 & 1.6162 & & 1. 6091 & & 1. 3322 & \\
\hline 32 & & 19.1 & Sine .... & 60.15 & 1. 6183 & 1.6178 & 1. 6105 & 1. 6103 & 1. 3328 & 1. 3328 \\
\hline 35 & ... & 19.3 & Sine.... & 60.11 & 1.6190 & & 1.6113 & & 1. 3333 & \\
\hline
\end{tabular}


ROSA, LLOYD, ] EFFECT OF WAVE FORM ON WATTMETERS.
REID.

Table III.-Table of Results of 49 Ruxs on Three Meters Using Sine, Peak and Flat Waves, etc.-Continued.

\begin{tabular}{|c|c|c|c|c|c|c|c|c|c|c|}
\hline \multirow{3}{*}{\begin{tabular}{l}
$\dot{\Xi}$ \\
\multirow{3}{*}{} \\
0 \\
$\dot{0}$ \\
$\dot{z}$
\end{tabular}} & \multirow{3}{*}{$\begin{array}{l}\text { Phase } \\
\text { of } \\
\text { har- } \\
\text { monic. }\end{array}$} & \multirow{3}{*}{$\begin{array}{c}\text { Lag of } \\
\text { cur- } \\
\text { rent. }\end{array}$} & \multirow{3}{*}{$\begin{array}{l}\text { Wave } \\
\text { form. }\end{array}$} & \multirow{3}{*}{$\begin{array}{c}\text { Fre- } \\
\text { quency. }\end{array}$} & \multicolumn{6}{|c|}{ Time in seconds for one revolution of disk. } \\
\hline & & & & & \multicolumn{2}{|c|}{ Meter No. 1.} & \multicolumn{2}{|c|}{ Meter No. 2.} & \multicolumn{2}{|c|}{ Meter No. 3.} \\
\hline & & & & & Time. & Mean. & Time. & Mean. & Time. & Mean. \\
\hline 30 & 60 & \multirow{2}{*}{$\begin{array}{c}18.1 \\
\cdots . . .\end{array}$} & \multirow{2}{*}{$\begin{array}{l}\text { Peak ... } \\
\text { Peak ... }\end{array}$} & \multirow{2}{*}{$\begin{array}{l}59.83 \\
60.11\end{array}$} & 1. 6234 & \multirow[t]{2}{*}{1.6239} & 1.6145 & \multirow[t]{2}{*}{1.6150} & 1. 3447 & \multirow{2}{*}{1.3448} \\
\hline 33 & 60 & & & & 1.6244 & & & & & \\
\hline 31 & 60 & 16.8 & Flat .... & 60.22 & 1.6143 & \multirow{2}{*}{1.6149} & 1.6087 & \multirow{2}{*}{ 1. 6089} & 1.3405 & \multirow{2}{*}{ 1. 3414} \\
\hline 34 & 60 & 16.3 & Flat .... & 60.10 & 1.6155 & & $1.6 C 91$ & & 1.3423 & \\
\hline 36 & & 20.0 & Sine. & 60.12 & 1.6184 & \multirow{3}{*}{1.6179} & 1.6116 & \multirow{3}{*}{1.6108} & 1. 3339 & \multirow{3}{*}{ 1. 3332} \\
\hline 39 & $\cdots$ & 20.1 & Sine .... & 60.20 & 1.6177 & & 1.6103 & & 1. 3330 & \\
\hline 41 & $\ldots$ & 20.1 & Sine .... & 60.25 & 1.6176 & & 1. 6104 & & 1.3326 & \\
\hline 37 & 30 & 19.5 & Peak ... & 60.12 & 1. 6222 & \multirow{2}{*}{1.6220} & 1.6132 & \multirow{2}{*}{1.6132} & 1.3457 & \multirow{2}{*}{ 1. 3455} \\
\hline 40 & 30 & ........... & Peak & 60.22 & 1.6219 & & 1.6131 & & 1.3454 & \\
\hline 38 & 30 & 17.5 & Flat .... & 60.17 & 1. 6169 & \multirow{2}{*}{ 1. 6182} & 1. 6104 & \multirow{2}{*}{ 1. 6110} & 1.3414 & \multirow{2}{*}{1.3415} \\
\hline 42 & 30 & ........ & Flat & 60.27 & 1.6195 & & 1. 6115 & & 1.3417 & \\
\hline 44 & & 20.2 & Sine. & & 1.6178 & \multirow{2}{*}{1.6177} & 1.6101 & \multirow{2}{*}{1.6106} & 1. 3326 & \multirow{2}{*}{ 1. 3327} \\
\hline 47 & ... & 20.4 & Sine. & 60.01 & 1.6176 & & 1. 6112 & & 1.3328 & \\
\hline 45 & 0 & ..... & Peak ... & ....... & 1.6191 & \multirow{2}{*}{1.6190} & 1.6104 & \multirow{2}{*}{1.6106} & 1.3453 & \multirow{2}{*}{1.3456} \\
\hline 49 & 0 & 22.0 & Peak ... & 60.11 & 1.6190 & & 1.6107 & & 1.3460 & \\
\hline 43 & 0 & ....... & Flat .... & ....... & 1.6216 & \multirow{2}{*}{ 1. 6220} & 1.6154 & 54 & 1.3424 & 26 \\
\hline 46 & 0 & 17.6 & Flat .... & 60.04 & 1.6224 & & 1.6154 & 1.0104 & 1.3429 & 1.3420 \\
\hline
\end{tabular}

Table IV.-Summary of Results Shown in Table III.

\begin{tabular}{|c|c|c|c|c|c|c|c|}
\hline \multirow{2}{*}{$\begin{array}{l}\text { Meter } \\
\text { No. }\end{array}$} & \multirow{2}{*}{$\begin{array}{l}\text { Phase } \\
\text { of har- } \\
\text { monic. }\end{array}$} & \multirow{2}{*}{ Sine. } & \multirow{2}{*}{ Peak. } & \multirow{2}{*}{$\begin{array}{l}\text { Per cent } \\
\text { slow. }\end{array}$} & \multirow{2}{*}{ Flat. } & \multicolumn{2}{|c|}{ Per cent. } \\
\hline & & & & & & Slow. & Fast. \\
\hline 1 & 0 & 1. 6166 & 1. 6186 & 0.12 & 1.6206 & 0.25 & \\
\hline 1 & 30 & 1. 6164 & 1. 6210 & 0.28 & 1. 6167 & 0.02 & \\
\hline 1 & 60 & 1. 6167 & 1. 6228 & 0.38 & 1. 6138 & ........ & 0.18 \\
\hline 1 & 90 & 1. 6151 & 1.6216 & 0.40 & 1.6125 & & 0.16 \\
\hline 2 & 0 & 1.6095 & 1. 6102 & 0.04 & 1. 6142 & 0.29 & \\
\hline 2 & 30 & - 1.6092 & 1. 6126 & 0.21 & 1. 6101 & 0.06 & \\
\hline 2 & 60 & 1. 6096 & 1. 6142 & 0.29 & 1. 6075 & . & 0.13 \\
\hline & & 等 & & & & & \\
\hline 3 & 0 & 1. 3318 & 1. 3444 & 0.95 & 1. 3412 & 0.70 & \\
\hline 3 & 30 & 1. 3318 & 1. 3448 & 0.98 & 1. 3410 & 0.69 & \\
\hline 3 & 60 & 1. 3318 & 1. 3437 & 0.89 & 1. 3402 & 0.63 & \\
\hline 3 & 90 & 1.3305 & 1. 3419 & 0.85 & 1. 3400 & 0.71 & \\
\hline
\end{tabular}


In Table IV the values given are the means of the two values found for the corresponding case and shown in Table III. Thus 1.6166 is the average of 1.6154 , the mean found for runs $1,4,7$ and

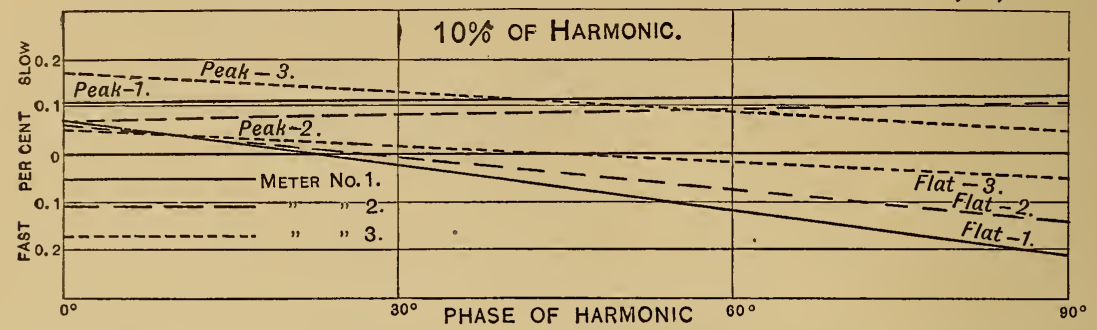

FIG. 6. - Showing the variation in the rate of three induction meters with 10 per cent harmonic in the current as the phase of the harmonic is changed from $0^{\circ}$ to $90^{\circ}$.

1.6177 , the mean of runs 44,47 . Likewise, 1.6186 is the average of 1.6183 (runs 2, 5) and 1.6190 (runs 45, 49). This eliminates effect of changing temperature during the course of the experiments.

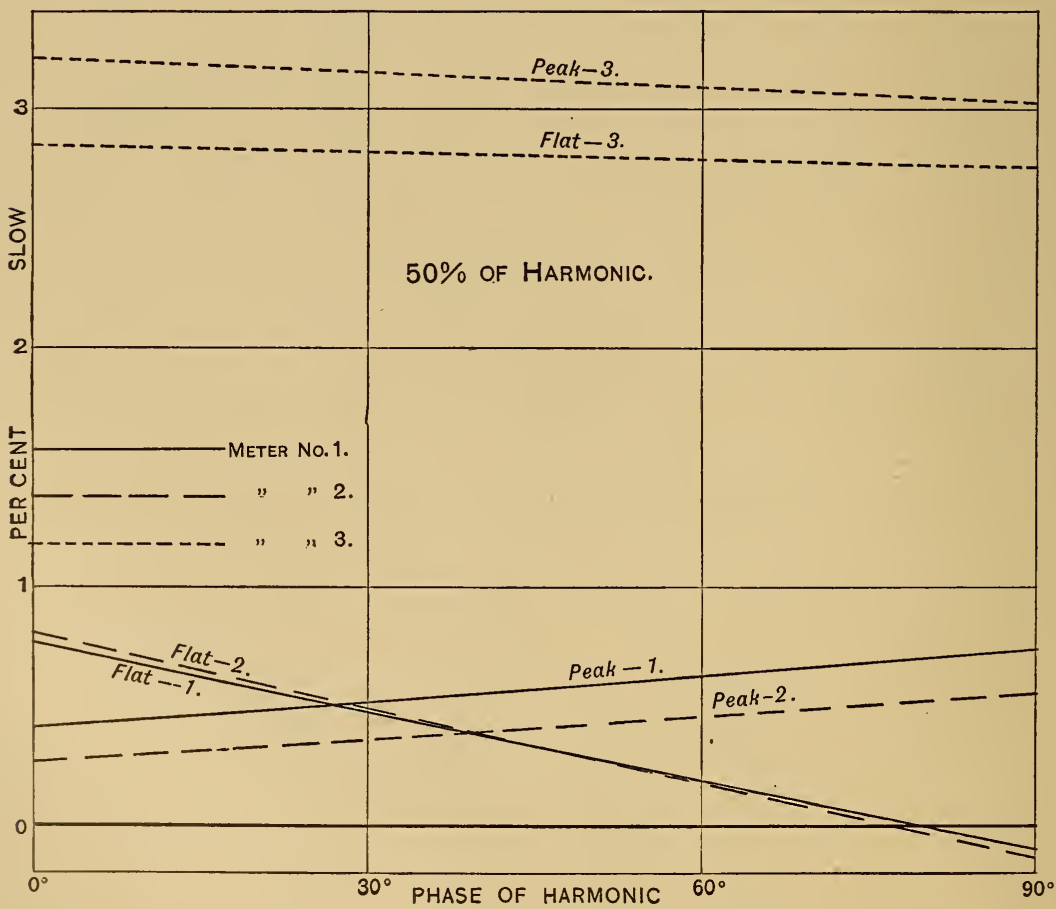

FIG. 7.-Showing the variation in the rate of three induction meters with 50 per cent harmonic in the current as the phase of the harmonic is changed from $0^{\circ}$ to $90^{\circ}$.

The maximum variation due to 25 per cent harmonic is, in the case of meter 3, a little less than 1 per cent, being greater with the peak than the flat, but not varying much with the phase of the 
harmonic. On the other hand, meters 1 and 2 show smaller errors due to the presence of the harmonic, but greater changes due to shifting the phase of the harmonic, both changing from slow to fast on the flat wave when the phase is shifted. Meter 4 runs faster for both peak and flat and at all phases than on a sine wave. It is the only meter of the five for which this is true.

Fig. 6 shows the effect of changing the phase of the harmonic from $0^{\circ}$ to $90^{\circ}$ when using a harmonic of 10 per cent, and fig. 7 shows the same for 50 per cent. Only three meters were used in these experiments.

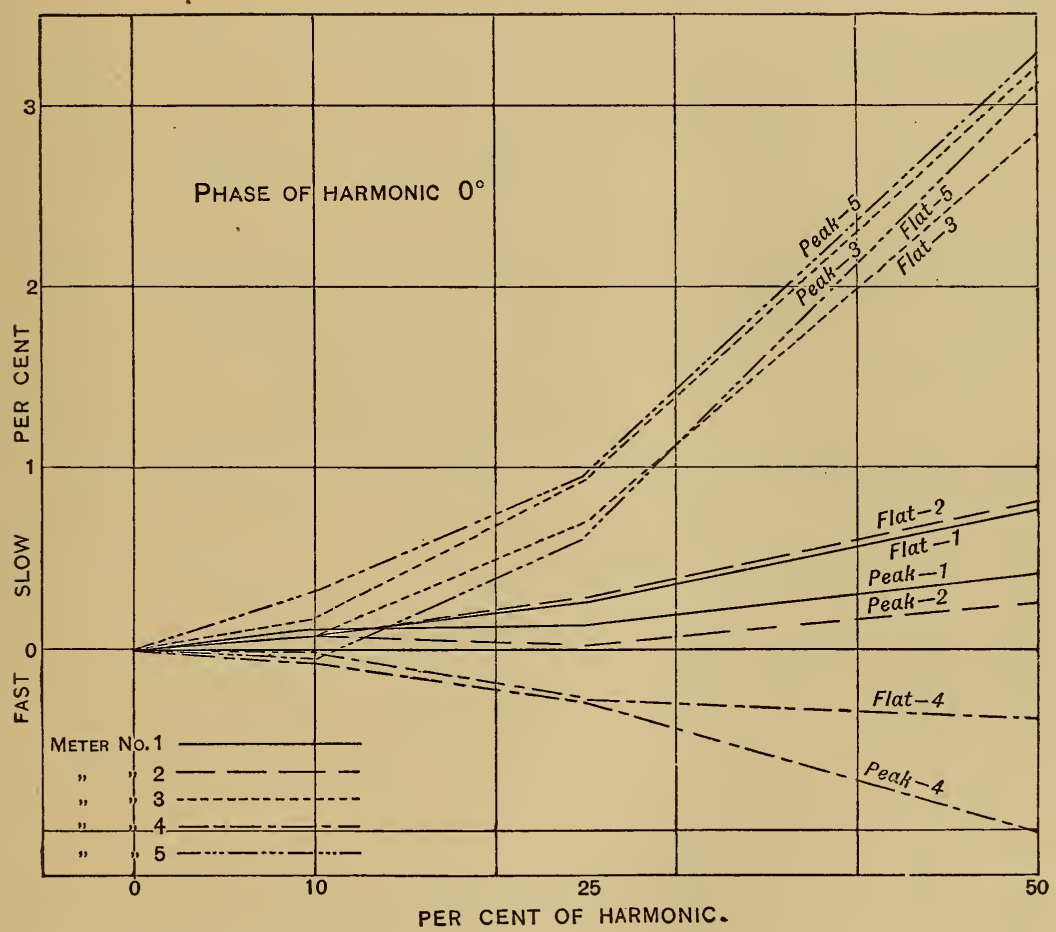

Fig. 8.-Showing the variation in the rate of five induction meters with 10,25 , and 50 per cent of harmonic, the phase of the harmonic in each case being $0^{\circ}$.

Fig. 8 shows the effect of changing the harmonic from 10 per cent to 25 per cent and 50 per cent, keeping the phase constant. Meters 1 and 2 show the least change in rate; meter 4 runs faster, and meters 3 and 5 run slower and show the greatest change in rate. Fig. 9 shows for three meters the same thing as fig. 8, except that the phase of the harmonic is $90^{\circ}$ different. Meters 1 and 2 show relatively small changes, but both run faster on the flat than on the sine. Meter 3 runs nearly 3 per cent slower on the 50 per cent harmonic than on the sine. 


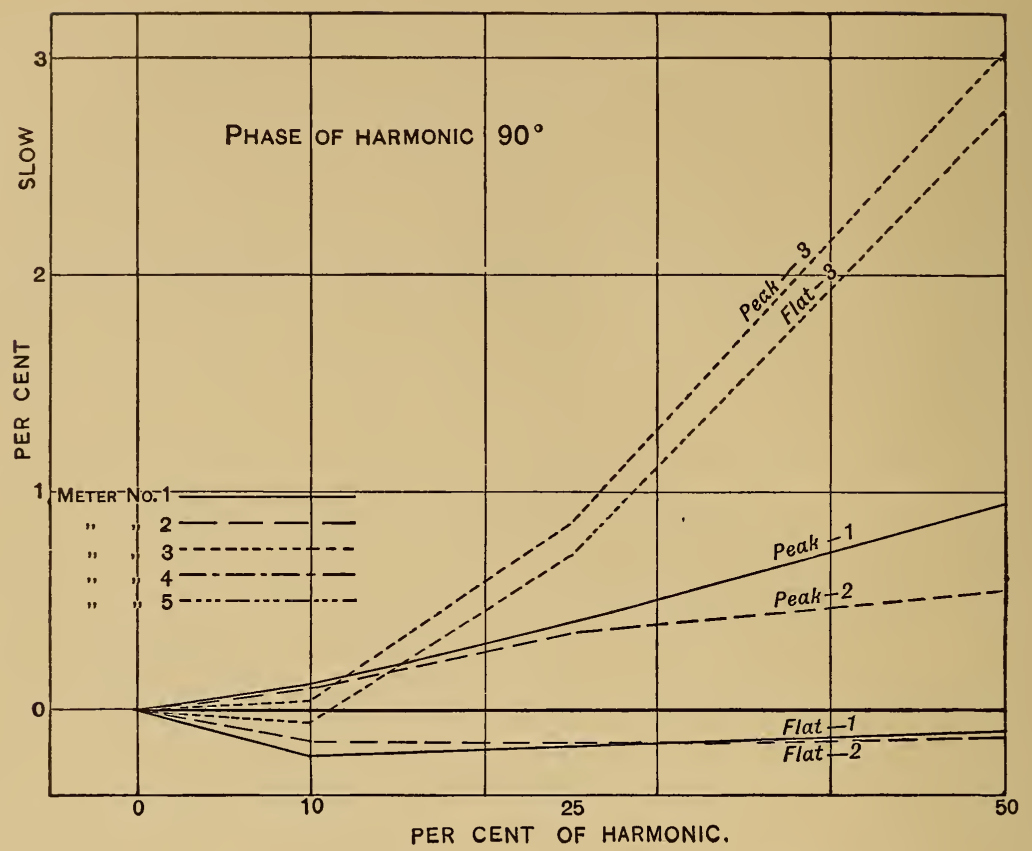

FIG. 9.-Showing the variation in the rate of three induction meters with 10,25 , and 50 per cent of harmonic, the phase of the harmonic in each case being $90^{\circ}$.

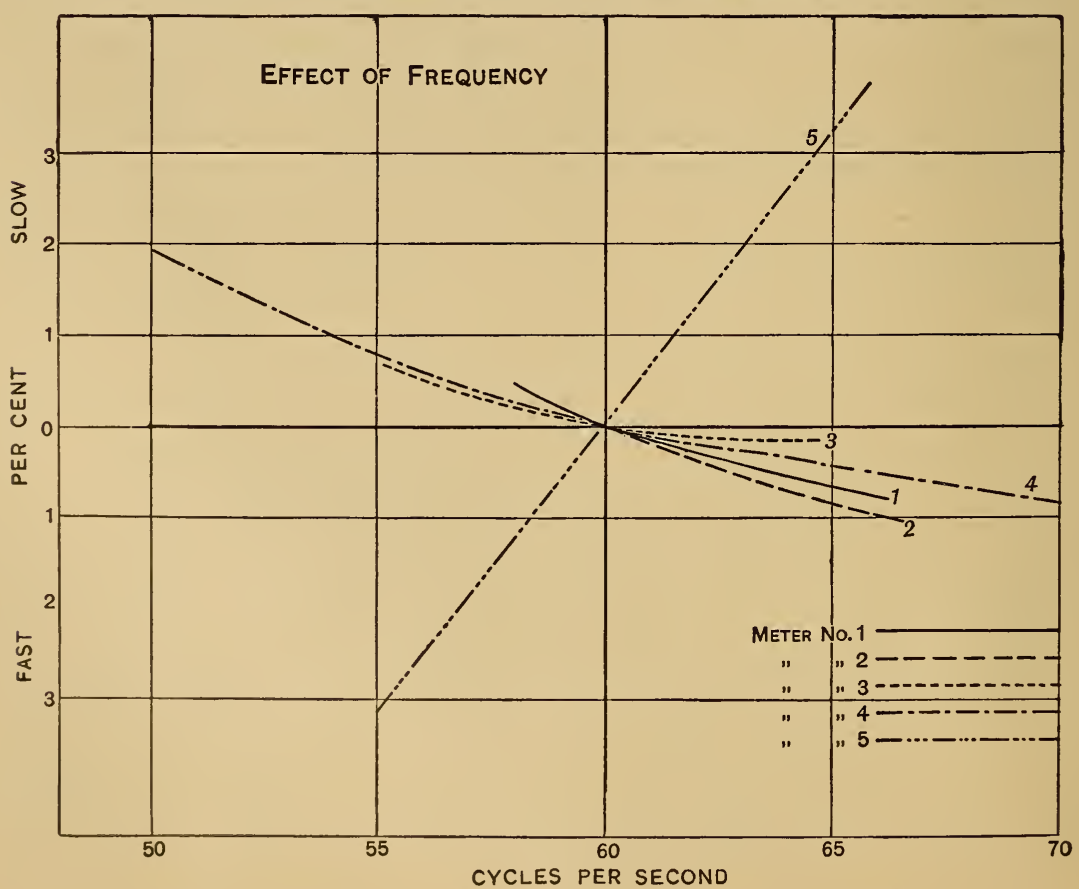

FIG. 10.-Showing the variation in the rate of five induction meters with change of frequency. 
ROSA, LLOYD, ] EFFECT OF WAVE FORM ON WATTMETERS.
REID.

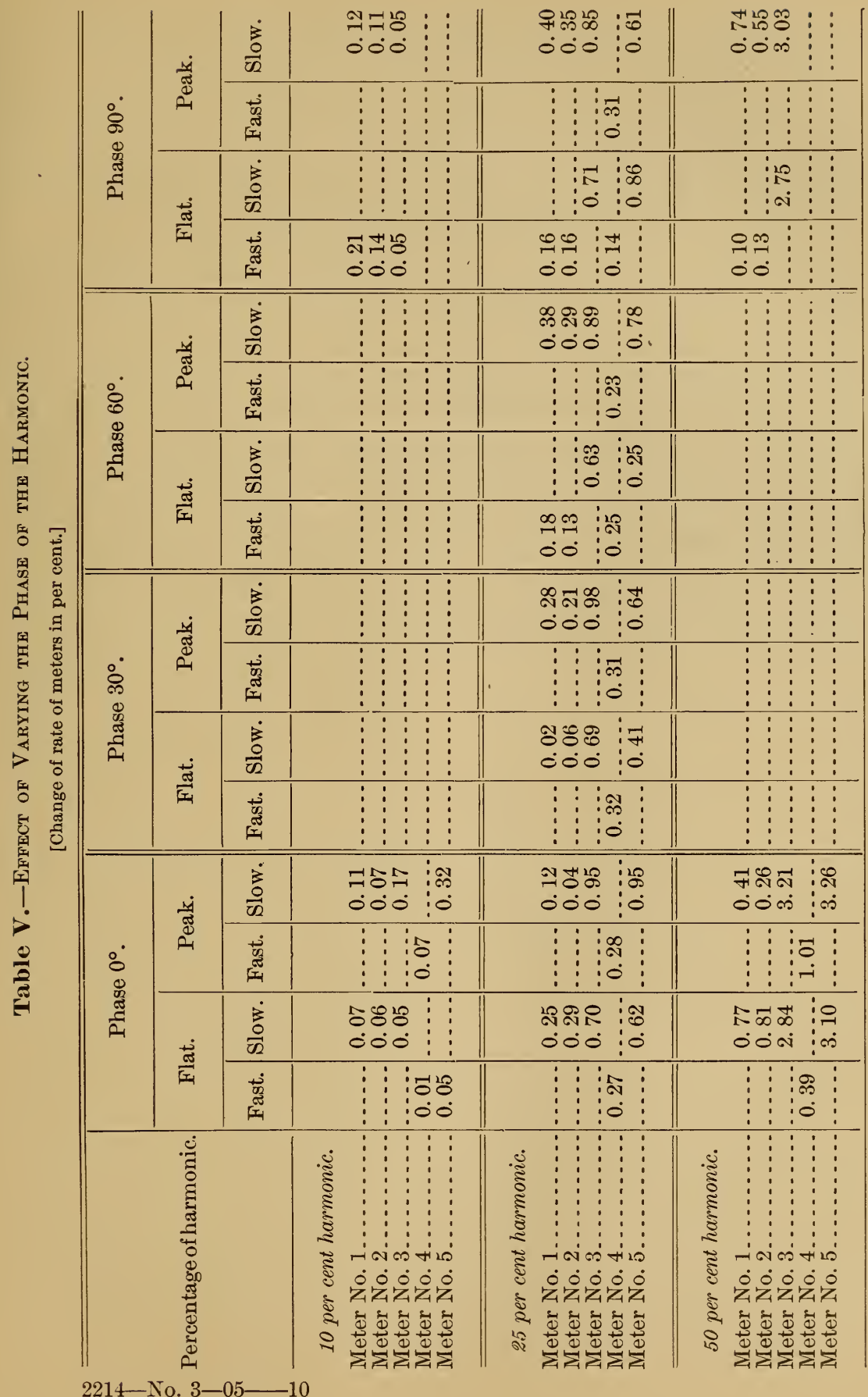


The effect of change of frequency on the rate of the meters is shown in fig. 10. It is relatively small in every case but one.

These results show that with suitable precautions induction meters may be made to repeat their readings very accurately, so that precision methods may be applied in studying them. They also show that the variations due to wave form depend not only on the harmonics which are present and their magnitudes, but also on their phases.

The Bureau of Standards is now having a generating set constructed which will give all the odd harmonics up to the fifteenth and any desired combination of them with the fundamental. When this is completed it will be used to study the effects of the higher harmonics on the rate of these meters. The results given here show that for commercial purposes all the meters so far studied may be considered accurate on any ordinary wave form where only the third harmonic enters appreciably, although two meters show variations of about 3 per cent when the harmonic amounts to as much as 50 per cent of the fundamental. 


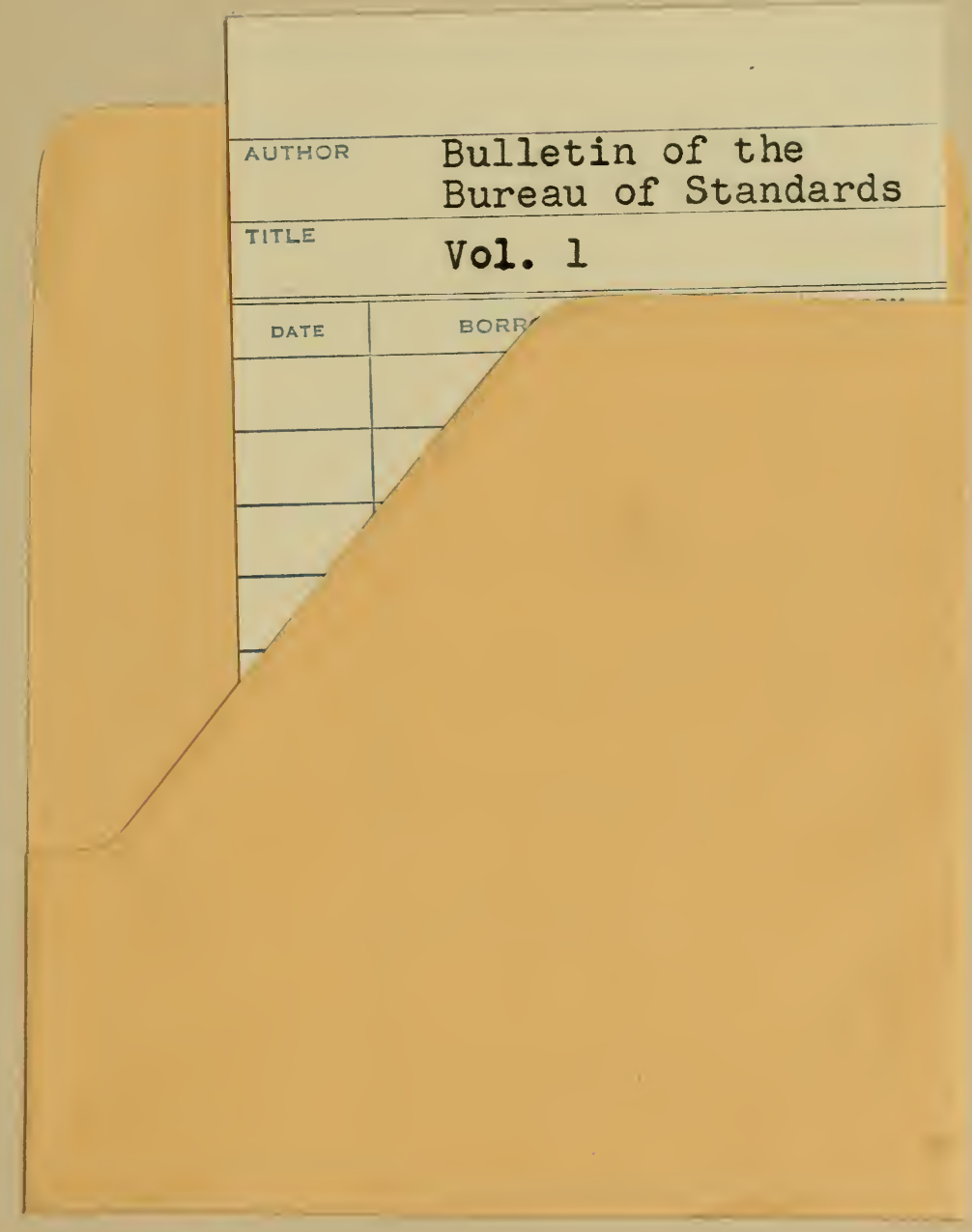


